\title{
FAKTOR - FAKTOR YANG MEMPENGARUHI LULUSAN SARJANA PENDIDIKAN EKONOMI TAHUN 2017 DALAM MEMILIH KARIR DIBIDANG NON KEPENDIDIKAN
}

\author{
Luh Merlinda Cindy ${ }^{1}$, Iyus Akhmad Haris² ${ }^{2}$ Kadek Rai Suwena ${ }^{3}$ \\ Jurusan Pendidikan Ekonomi, Fakultas Ekonomi \\ Universitas Pendidikan Ganesha Singaraja, \\ Indonesia
}

email: \{merlindacindy@yahoo.com¹, iyusharis55@gmail.com², kadek suwena@yahoo.co.id $\left.{ }^{3}\right\}$

\begin{abstract}
Abstrak
Penelitian ini bertujuan untuk mengetahui faktor - faktor yang mempengaruhi dalam memilih karir. Rancangan yang digunakan dalam penelitian ini adalah jenis rancangan penelitian faktorial. Penelitian ini dilakukan di Jurusan Pendidikan Ekonomi Fakultas Ekonomi Universitas Pendidikan Ganesha yang terletak di Jalan Udayana, Singaraja. Jumlah sampel yang diguanakan sebanyak 43 orang Lulusan Sarjana Pendidikan Ekonomi tahun 2017 yang bekerja diluar bidang pendidikan. Teknik analisis data yang digunakan adalah analisis faktor. Berdasarkan hasil analisis menunjukan bahwa faktorfaktor yang mempengaruhi pemilihan karir non pendidikan alumni Jurusan Pendidikan Ekonomi Fakultas Ekonomi Universitas Pendidikan Ganesha, adalah sebanyak 23 (dua puluh tiga) indikator dari 5 faktor diantaranya: Faktor penghargaan finansial, terdiri dari 3 (tiga) indikato. Faktor pasar kerja, terdiri dari 5 (lima) indicator. Faktor profesional, terdiri dari 4 (empat) indicator. Faktor nilai sosial, terdiri dari 4 (empat) indicator. Faktor lingkungan kerja, terdiri dari 7 (tujuh) indikator. Faktor yang paling dominan mempengaruhi adalah faktor pengharggan finansial dengan Eigen value $=7.797$. Dari penelitian ini, diharapkan para sarjana memilih karir yang menjanjikan dan yang cocok dengan kepribadiannya.
\end{abstract}

Kata kunci: faktor dalam memilih karir.

\begin{abstract}
This study aims to determine the factors that influence the careers election. The design used in this study is a factorial research design type. This research was conducted at the Economic Education Department, Economic faculty of Ganesha University that located on Jalan Udayana, Singaraja. The number of samples is 43 people, which graduated of the Economic Education in 2017 who work outside the field of education. The data analysis technique used is factor analysis. Based on the results of the analysis showed that the factors influenced the selection of non-education career alumni of the Economic Education Department Economics Faculty of Ganesha University are 23 (twenty three) indicators of 5 factors including: Factors of financial rewards, consisting of 3 (three) indicators. Labor market factors, consisting of 5 (five) indicators. Professional factors, consisting of 4 (four) indicators. Factors of social value, consisting of 4 (four) indicators. Work environment factors, consisting of 7 (seven) indicators. The most dominant factor influencing is the financial reward factor with Eigen value $=7.797$. From this study, it is expected that scholars choose promising careers and those that fit their personality.

Keywords: factors in choosing a career.
\end{abstract}




\section{PENDAHULUAN}

Pemilihan karir merupakan salah satu proses pembuatan keputusan terpenting dalam kehidupan individu. Keputusan yang dibuat akan berdampak pada apa yang dilalui dalam hidupnya. Pemilihan karir juga merupakan aspek kehidupan seseorang yang tidak dapat terelakan karena hal tersebut merupakan salah satu proses pembuatan keputusan setelah individu melewati beberapa tahap perkembangan dalam hidupnya. Memilih sebuah karir lebih dari sekedar menentukan apa yang akan dilakukan seseorang untuk mencari nafkah. Selain itu menurut Peter M. Blau (Akbar, 2011) pilihan seseorang terhadap suatu pekerjaan didorong oleh faktor adanya kecenderungan untuk mendapatkan ganjaran dan faktor pengharapan terhadap terjadinya perubahan. Jika karir sesuai dengan minat, maka harapan seseorang akan tercapai dan menjadikan perubahan dalam hidupnya. Menurut Stolle (dalam Suyono, 2014) faktor yang mempengaruhi minat dalam memilih karir terdiri dari 5 macam, diantaranya penghargaan finansial, lingkungan kerja, pelatihan profesional, nilai sosial, dan pasar kerja.

Selain itu salah satu faktor yang membentuk karir seseorang adalah pendidikan yang telah ditempuhnya, bagi mereka yang telah lulus menjadi sarjana merupakan keputusan yang penting, karena akan menentukan masa depan mereka. Empat tahun (atau lebih) mahasiswa tidak selamanya berada di lingkungan pendidikan tidak selalu membuat mereka mengerti apa yang ingin mereka lakukan. Lebih buruk lagi jika mereka tidak banyak berkecimpung didunia organisasi ataupun eksrakurikuler. Semakin sedikit hal mereka ketahui, biasanya mereka memiliki dua pilihan dalam penetuan karirnya, pertama adalah menciptakaan pekerjaan sendiri (wiraswasta), sementara kedua adalah mencari kerja sebagai karyawan. Saat ini banyak lulusan terdidik mulai melirik jalur karir lain tidak sesuai dengan bidangnya untuk mereka jalankan nantinya karena sangat tingginya tingkat persaingan dan perubahan minat karir seseorang. Dengan tingkat persaingan yang tinggi dan bahkan mungkin tingkat kemampuan dan keahlian masing-masing mahasiswa berbeda tidak menutup kemungkinan mereka akan berkarir di luar bidang lainnya yang mungkin masih berhubungan dengan jurusannya dan sesuai dengan minat dan bakat yang dimiliki. Dengan kata lain setelah menyelesaikan pendidikan jenjang program sarjana pendidikan, setiap sarjana khususnya sarjana pendidikan bebas untuk memilih karir yang akan dijalaninya sesuai dengan keinginan dan harapannya masing-masing mahasiswa.

Seperti halnya di Jurusan Pendidikan Ekonomi, Fakultas Ekonomi Universitas Pendidikan Ganesha banyak para lulusan sarjana pendidikan ekonomi yang melanjutkan profesi diluar bidangnya. Dari data yang diperoleh alumni lulusan sarjana pendidikan ekonomi tahun 2017 yang berjumlah 67 orang. Jika di jabarkan sebesar $65 \%$ (43 orang) bekerja di luar bidang pendidikan dan 35\% (24 orang) bekerja di bidang pendidikan. Hal ini sangat berbanding terbalik dengan tujuan awal masuk di jurusan Pendidikan Ekonomi. Dengan demikian, menarik untuk diteliti, faktor-faktor apa saja yang mempengaruhi mahahasiwa lulusan sarjana pendidikan dalam pemilihan 
karirnya. Alasan dilakukan penelitian ini guna untuk mengetahui mengapa lulusan sarjana pendidikan ekonomi banyak memilih karir diluar bidangnya, sehingga akan menjadi wawasan bagi mahasiswa dalam memilih karir dan menghadapi persaingan dunia kerja.

\section{METODE PENELITIAN}

Rancangan yang digunakan dalam penelitian ini adalah jenis rancangan penelitian faktorial. Menurut Suliyanto (2005) analisis faktor adalah suatu teknik yang digunakan untuk menganalisis tentang saling ketergantungan (interindependence) dari beberapa variabel secara simultan menjadi sejumlah faktor yang lebih sedikit dari variabel yang diteliti. Penelitian ini dilakukan untuk mencari faktorfaktor yang mempengaruhi pemilihan karir non pendidikan lulusan sarjana Pendidikan Ekonomi tahun 2017 Fakultas Ekonomi Universitas Pendidikan Ganesha dan untuk mengetahui faktor yang paling dominan yang mempengaruhi pemilihan karir non pendidikan.

Menurut Sugiyono (2012) "populasi adalah wilayah generalisasi yang terdiri dari obyek atau subyek yang mempunyai kualitas dan karakteristik tertentu yang ditetapkan oleh peneliti untuk dipelajari dan kemudian ditarik kesimpulannya". Populasi dalam penelitian ini adalah alumni Jurusan Pendidikan Ekonomi tahun 2017 Universitas Pendidikan Ganesha yang berjumlah 67 orang.

Sampel adalah bagian dari jumlah dan karakteristik yang dimiliki oleh populasi (Sugiyono, 2012) dalam penelitian ini sampel yang diambil sebanyak 43 orang yang bekerja diluar bidang kependidikan ditentukan dengan metode sensus.
Dalam penelitian ini peneliti menggunakan jenis data kualitatif. Data kualitatif yang dimaksud dalam penelitian ini adalah data yang berupa hasil dari penyebaran kuesioner. Data kuantitatif yang dimaksud dalam penelitian ini adalah jumlah mahasiswa alumni yang digunakan sebagai sampel.

Jenis data menurut sumbernya dalam penelitian ini menggunakan data primer dan data sekunder. Data primer yang dimaksud dalam penelitian ini adalah data yang diperoleh langsung dari tempat penelitian, melalui, dokumentasi, wawancara, kuesioner. Sedangkan data sekunder yang dimaksud dalam penelitian ini yaitu data yang merupakan hasil pengumpulan orang lain atau instansi lain yang berbentuk publikasi seperti stuktur organisasi, jumlah mahasiswa.

Instrumen penelitian yang digunakan adalah kuesioner yang disebarkan secara online yang dimana menggunakan Skala Likert untuk mengukur data yang diperoleh. Pada penelitian ini digunakan skala likert yaitu skala lima tingkat yang terdiri dari: sangat tidak setuju (Nilai 1), tidak setuju (Nilai 2), kurang setuju (Nilai 3), setuju (Nilai 4), dan sangat setuju (Nilai 5). Pengujian instrumen dalam penelitian ini menggunakan uji validitas dan uji reliabilitas. Uji validitas merupakan derajat ketepatan antara data yang terjadi pada obyek penelitian dengan daya yang dapat dilaporkan oleh peneliti. Teknik yang dipergunakan dalam menguji validitas adalah korelasi bevariate pada $\alpha=5 \%$. Perhitungan koefisien korelasi menggunakan pendekatan product moment CoEfficient dari Karl Pearson dengan menggunakan bantuan SPSS (Statistical Program Social Science) versi 22.0 for windows. Sedangkan 
Uji realibilitas adalah untuk mengetahui sejauh mana hasil pengukuran tetap konsisten, apabila dilakukan pengukuran dua kali atau lebih terhadap gejala yang sama dengan menggunakan alat pengukuran yang sama, pada penelitian ini uji realibilitas diukur menggunakan teknik pengujian dengan metode alpha cronbach dengan bantuan SPSS (Statistical Program Social Science) versi 22.0 for windows.

Teknik analisis data yang digunakan untuk mengetahui faktor - faktor yang mempengaruhi lulusan sarjana pendidikan ekonomi tahun 2017 dalam memilih karir dibidang non kependidikan adalah analisis faktor. Teknik sistematika analisis faktor pada awalnya dikembangkan oleh spearman (1904), analisis factor konfirmatori (CFA) yaitu suatu teknik analisis faktor dimana secara apriori berdasarkan teori dan konsep yang sudah diketahui dipahami atau ditentukan sebelumnya. Dalam penelitian ini tujuan digunakannya teknik analisis faktor ini adalah untuk menegtahui faktor-faktor pemilihan karir non akademik.

\section{HASIL DAN PEMBAHASAN Hasil Penelitian}

Dalam melakukan analisis faktor keputusan pertama yang harus diambil adalah menganalisis apakah data yang ada cukup memenuhi syarat dalam analisis faktor. Langkah pertama yang dilakukan dengan mencari korelasi matrix antara indikator-indikator yang diobservasi. Korelation matrix atau anti-image digunakan untuk memenuhi syarat analisis faktor. Hasil pengujian menunjukkan nilai determinasi matrik 0,0015.

Adapun nilai anti-image correlation ditunjukkan dengan nilai MSA sebagai berikut. Keiser-Mayer Olkin (KMO).Metode KMO mengukur kecukupan sampling secara menyeluruh dan untuk mengukur kecukupan sampling untuk setiap indikator. Metode ini mengukur homogenitas indikator.

\section{Tabel 2. Hasil Pengujian Homogenitas}

KMO and Bartlett's Test

\begin{tabular}{llr}
\hline Kaiser-Meyer-Olkin Measure of Sampling Adequacy. & .660 \\
\hline Bartlett's Test of Sphericity & Approx. Chi- & 638.093 \\
& Square & \\
Df & 253 \\
& Sig. & .000 \\
\hline
\end{tabular}

Berdasarkan hasil pengujian KMO diperoleh nilai Kaiser-MeyerOlkin Measure of Sampling Adequacy sebesar 0,660 termasuk dalam kategori biasa (middling). Namun telah memenuhi criteria $K M O$ karena lebih besar dari 0,5. Bartlett's test of sphericity. Uji
Bartlett ini meupakan uji statistik untuk signifikasi menyeluruh dari semua korelasi didalam matrik korelasi. Didalam hal ini kita menguji hipotesis nol bahwa data yang diobservasi merupakan sampel dari distribusi populasi normal multivariate yang mana koefisien 
korelasi besarnya nol. Uji ini diproksi dengan menggunakan uji distribusi Chi Squares. Berdasarkan Tabel 2 diperoleh nilai Bartlett's Test of Sphericity Approx. Chi-Square sebesar 638.093 pada df 253 dengan nilai signifikansi sebesar $0,000<0.5$. Ekstrasi Faktor. Ekstraksi faktor adalah suatu metode yang digunakan untuk meredukasi data dari beberapa indikator untuk menghasilkan faktor yang lebih sedikit yang mampu menjelaskan korelasi antara indikator yang diobservasi. Metode yang digunakan untuk melakukan ekstraksi factor adalah Parcial Components Analysis. Metode ini membentuk kombinasi linier dari indikator yang observasi. Komponen utama yang pertama adalah kombinasi yang menjelaskan jumlah varian yang paling besar dari sampel.Selanjutnya komponen utama kedua adalah menjelaskan jumlah varian yang paling besar kedua dan tidak berhubungan dengan komponen utama pertama. Komponen utama berikutnya menjelaskan porsi yang lebih kecil dari varian sampel total dan tidak berhubungan dengan yang lainnya. Dengan menggunakan metode Principal Componen Analisis (PCA) diperoleh 5 (lima) faktor yang mempengaruhi pemilihan karir non pendidikan alumni Universitas Pendidikan Ganesha.

Kelima faktor tersebut mampu menjelaskan semua varian yang ada dalam data sebesar $73,623 \%$ seperti yang ditunjukkan secara rinci pada Tabel 3 berikut.

Tabel 3. Eigen Value, Percent of Variance dan Total Cumulative of Variance dari 5 (Lima) faktor yang mempengaruhi pemilihan karir non pendidikan alumni Universitas Pendidikan Ganesha

\begin{tabular}{lccc}
\hline \multicolumn{1}{c}{ Faktor } & Eigen Value & \% of Variance & Cumulative \% \\
\hline Penghargaan Finansial & 7.797 & 33.901 & 33.901 \\
Pelatihan Profesional & 3.060 & 13.306 & 47.206 \\
Lingkungan Kerja & 1.926 & 8.372 & 55.578 \\
Nilai Sosial & 1.319 & 5.737 & 61.315 \\
Pasar Kerja & 1.252 & 5.443 & 66.758 \\
\hline
\end{tabular}

Dari Tabel 3 dapat dilihat eigen value berada pada interval 1,252 sampai 7,797 . Kelima faktor tersebut merupakan faktor-faktor yang mempengaruhi pemilihan karir non pendidikan alumni Jurusan Pendidikan Ekonomi Fakultas Ekonomi Universitas Pendidikan Ganesha. Berdasarkan eigen value, faktor yang paling representatif untuk mewakili sekelompok variabel adalah faktor 1 dilihat dari eigen value yang paling besar yaitu 7,797 . Berdasarkan pada nilai percent of variance, diketahui faktor yang menyumbangkan bagian variasi terbesar keseluruhan yang dianalisis adalah faktor 1 sebesar $33,901 \%$. Nilai total cumulative of variance sebesar $66,758 \%$ digunakan untuk menjelaskan kelima faktor yang mempengaruhi pemilihan karir non pendidikan alumni Jurusan Pendidikan Ekonomi tahun 2017 Fakultas Ekonomi Universitas Pendidikan Ganesha. Rotasi faktor. Rotasi faktor digunakan jika metode ekstraksi faktor belum menghasilkan komponen faktor utama yang jelas. Tujuan dari rotasi faktor adalah agar dapat memperoleh struktur faktor 
yang lebih sederhana agar mudah diinterprestasikan. Penelitian ini menggunakan pendekatan varimax dimana varimax method adalah rotasi orthogonal untuk meminimalisir jumlah indikator yang mempunyai factor loading tinggi pada tiap faktor.

Rotasi faktor digunakan untuk menyederhanakan matrik faktor yang memiliki struktur yang masih sulit untuk diinterpretasikan. Oleh karena itu diupayakan dengan melakukan rotasi faktor, diperoleh struktur yang sederhana sehingga mudah untuk menjelaskan seluruh faktor yang dianalisis dalam model.

Dalam penelitian ini digunakan rotasi varimax, rotasi varimax dipilih karena hasil pengelompokkan mudah dianalisis secara teori maupun sejalan dengan penelitian terdahulu dan bersifat orthogonal yaitu faktor satu dengan yang lain tidak berkorelasi. Hasil rotasi faktor menunjukkan bahwa ada 23 indikator yang tersebar ke dalam 5 (lima) faktor yang merupakan faktorfaktor yang mempengaruhi pemilihan karir non pendidikan alumni Universitas Pendidikan Ganesha. f) Interpretasi faktor. Interpretasi faktor dilakukan dengan mengelompokkan variabel yang mempunyai faktor loading minimal 0,5 , sedangkan variabel yang mempunyai faktor loading kurang dari 0,5 dikeluarkan dari model.

Angka ini memperlihatkan bahwa penelitian ini mampu menjelaskan faktor-faktor yang mempengaruhi pemilihan karir non pendidikan alumni Universitas Pendidikan Ganesha sebesar $66,758 \%$.

Penghargaan finansial. Faktor pengargaan financial termasuk faktor-faktor yang yang mempengaruhi pemilihan karir non pendidikan alumni Jurusan
Pendidikan Ekonomi Fakultas Ekonomi Universitas Pendidikan Ganesha (eigen value $=7.797$ ). Indikator yang tercakup pada faktor ini terdiri dari 3 (tiga) indikator, yaitu : gaji awal yang tinggi, potensi kenaikan penghargaan finansial/gaji, tersedianya dana pensiun. Faktor ini menjelaskan keragaman dari variabel sebesar $33.901 \%$. Dari 3 (tiga) indikator yang ditemukan, indikator 1 mempunyai nilai varian yang paling besar dari indikatorindikator lainnya. Dengan demikian dapat disimpulkan faktor ini merupakan faktor yang paling mempengaruhi pemilihan karir non pendidikan alumni Jurusan Pendidikan Ekonomi Fakultas Ekonomi Universitas Pendidikan Ganesha.

Pelatihan Profesional. Faktor pelatihan profesional termasuk faktor-faktor yang mempengaruhi pemilihan karir non pendidikan alumni Jurusan Pendidikan Ekonomi Fakultas Ekonomi Universitas Pendidikan Ganesha (eigen value =3.060). Indikator yang tercakup pada faktor ini terdiri dari 4 (empat) indikator, yaitu pelatihan kerja sebelum memulai bekerja, pelatihan diluar lembaga untuk meningkatkan professional, pelatihan rutin di dalam lembaga, dapat memperoleh pengalaman kerjayang bervariasi.

Lingkungan Kerja. Llingkungan kerja termasuk faktor-faktor yang mempengaruhi pemilihan karir non pendidikan alumni Jurusan Pendidikan Ekonomi Fakultas Ekomomi Universitas Pendidikan Ganesha (Eigen value =1.926). Indikator yang tercakup pada faktor ini terdiri dari 2 (dua) indikator, yaitu: lingkungan pekerjaan rutin, lingkungan kerja yang menyenangkan, tekanan kerja untuk mencapai hasil yang sempurna, tekanan kerja untuk mencapai hasil 
yang sempurna, pekerjaan yang dilakoni merupakaan karir yang bergengsi, karyawan menaati kode etik kerja, kebebasan mengembangkan keahlian di bidang lain. Faktor ini menjelaskan keragaman dari variabel sebesar 8.372\%.

Faktor nilai sosial termasuk faktor-faktor yang mempengaruhi pemilihan karir non pendidikan alumni Jurusan Pendidikan Ekonomi Fakultas Ekonomi Universitas Pendidikan Ganesha (eigen value =1.319). Indikator yang tercakup pada faktor ini terdiri dari 4 (empat) indikator, yaitu: perlu kesempatan untuk berinteraksi dengan orang lain, lebih memberikan kepuasan pribadi, memperhatikan perilaku individu, memberikan kesempatan menyalurkan hobi. Faktor ini menjelaskan keragaman dari variabel sebesar $5.737 \%$.

Faktor pasar kerja termasuk faktor-faktor yang mempengaruhi pemilihan karir non pendidikan alumni Jurusan Pendidikan Ekonomi Fakultas Ekonomi Universitas Pendidikan Ganesha (eigen value =1.252). Indikator yang tercakup pada faktor ini terdiri dari 5 (lima) indikator, yaitu : keamanan kerja yang terjamin, kemudahan mengakses lowongan kerja, flesibelitas karir, kesempatan promosi, stabilitas emosi yang baik. Faktor ini menjelaskan keragaman dari variabel sebesar $5.443 \%$

Langkah terakhir dari analisis faktor adalah penentuan ketepatan model. Model faktor perlu diuji ketepatannya untuk mengetahui apakah model mampu menjelaskan dengan akurat. Dasar pengujiannya adalah dengan melihat prosentase jumlah residual yaitu perbedaan antara nilai korelasi awal dengan korelasi hasil reproduced. Hasil analisis faktor pada Lampiran 6 diketahui nilai prosentase residualnya adalah $39 \%$ atau sebanyak 96 residual. Hal ini menunjukkan bahwa model memiliki ketepatan sebesar $39 \%$ pada tingkat penyimpangan $5 \%$. Hal ini berarti model faktor dapat diterima.

\section{Pembahasan}

Setelah data dianalisis dilakukan pembahasan untuk mengetahui makna yang lebih luas dari hasil deskripsi data dan hasil analisis data. Terpenuhi kebutuhan pendidikan merupakan harapan bangsa, namun peluang kerja yang ada kadang tidak sesuai dengan kebutuhan lulusan yang dihasilkan oleh sebuah universitas. Penting bagi mahasiswa untuk lebih selektif dalam pemilihan jurusan ekonomi pada Universitas Pendidikan Ganesha dalam menentukan karir. Melalui analisis faktor akan dapat menjawab masalah tersebut.

Faktor-faktor

yang mempengaruhi pemilihan karir Lulusan Sarjana Pendidikan Ekonomi tahun 2017 Fakultas Ekonomi Universitas Pendidikan Ganesha dalam penelitian ini dapat diidentifikasikan terdiri dari 23 (dua puluh tiga) indikator dari 5 (lima) faktor. Faktor penghargaan finansial (gaji awal yang tinggi, potensi kenaikan penghargaan finansial/gaji, tersedianya dana pensiun). faktor pelatihan profesional (pelatihan kerja sebelum memulai bekerja, pelatihan diluar lembaga untuk meningkatkan professional, pelatihan rutin di dalam lembaga, dapat memperoleh pengalaman kerja yang bervariasi). Faktor nilai sosial (perlu kesempatan untuk berinteraksi dengan orang lain, lebih memberikan kepuasan pribadi, memperhatikan perilaku individu, memberikan kesempatan menyalurkan hobi). Faktor lingkungan kerja (lingkungan 
pekerjaan rutin, lingkungan kerja yang menyenangkan, tekanan kerja untuk mencapai hasil yang sempurna, tekanan kerja untuk mencapai hasil yang sempurna, pekerjaan yang dilakoni merupakaan karir yang bergengsi, karyawan menaati kode etik kerja, kebebasan mengembangkan keahlian di bidang lain). Faktor pasar kerja (keamanan kerja yang terjamin, kemudahan mengakses lowongan kerja, fleksibelitas karir, kesempatan promosi, stabilitas emosi yang baik).

Menentukan berapa faktor yang dapat diterima secara empirik dapat dilakukan berdasarkan besarnya eigen value setiap faktor yang muncul. Semakin besar eigen value setiap faktor, semakin representatif faktor tersebut untuk mewakili sekelompok indikator. Faktor-faktor inti yang dipilih adalah faktor yang mempunyai eigen value sama dengan atau lebih dari 1. Hasil rotasi faktor dengan menggunakan rotasi varimax diketahui terdapat 23 (dua puluh tiga) indikator yang tersebar ke dalam 5 (lima) faktor yang merupakan faktor-faktor yang mempengaruhi pemilihan karir non pendidikan alumni Jurusan Pendidikan Ekonomi Tahun 2017 Fakultas Ekonomi Universitas Pendidikan Ganesha. Selanjutnya dilakukan interpretasi faktor dengan mengelompokkan variabel yang mempunyai faktor loading minimal 0,5 , sedangkan variabel yang mempunyai faktor loading kurang dari 0,5 dikeluarkan dari model.

Dari 5 (lima) faktor tersebut, indikator yang mewakili setiap faktor yang mempengaruhi pemilihan karir non kependidikan mahasiswa lulusan Sarjana Pendidikan Ekonomi Tahun 2017 Fakultas Ekonomi Universitas Pendidikan Ganesha adalah indikator yang memiliki faktor loading terbesar dari masing-masing faktor, yaitu : Faktor Penghargaan Finansial diwakili oleh indikator gaji yang cukup dengan faktor loading 0.673. Faktor Pelatihan Profesional oleh indikator pelatihan luar lembaga dengan faktor loading 0.514 . Faktor Lingkungan Kerja diwakili oleh indikator faktor mengembangkan keahlian lain loading 0.258. Faktor Nilai Sosial untuk hasil yang sempurna oleh indikator memberikan rasa senang dengan faktor loading 0.171. Faktor Pasar Kerja diwakili oleh indikator menjalin kesepakatan dengan faktor loading 0.274 . Dengan demikian, faktor yang paling dominan mempengaruhi lulusan Sarjana Pendidikan Ekonomi alumni Jurusan Pendidikan Ekonomi Tahun 2017 Fakultas Ekonomi Universitas Pendidikan Ganesha dalam memilih karir dibidang non kependidikan adalah faktor penghargaan finansial.

Hasil diatas berarti bahwa dalam memilih karir dipengaruhi oleh lima faktor yaitu: penghargaan finansial, pelatihan professional, lingkungan kerja, nilai sosial dan pasar kerja. Sedangkan faktor dominan yang paling mempengaruhi pemilihan karir adalah faktor penghargaan finansial. Pemilihan karir juga harus berdasarkan minat dan sesuai dengan jurusan yang ditempuh selama pendidikan, agar tidak terjadi penyimpangan dalam menjalankan profesi karirnya.

\section{SIMPULAN DAN SARAN}

Berdasarkan hasil analisis data dan pembahasan, maka dapat ditarik simpulan sebagai berikut : Faktor-faktor yang mempengaruhi pemilihan karir non kependidikan mahasiswa lulusan Sarjana Pendidikan Ekonomi Tahun 2017 Universitas Pendidikan Ganesha, adalah sebanyak 5 (lima) faktor dari 23 (dua puluh tiga) indikator. Faktor 
dan indikator dapat dijelaskan sebagai berikut. Faktor penghargaan finansial, terdiri dari 3 (tiga) indikator, yaitu : gaji yang cukup, peluang kenaikan gaji, dan tunjangan dan pensiun. Faktor pelatihan profesional, terdiri dari 4 (empat) indikator, yaitu : pelatihan sebelum memulai pekerjaan, pelatihan luar lembaga, pelatihan rutin, pelatihan kerja bervariasi. Faktor lingkungan kerja, terdiri dari 7 (tujuh) indikator, yaitu : lingkungan kerja yang dilakukan secara rutin, lingkungan kerja yang menyenangkan, lingkungan kerja yang mempengaruhi pekerjaan, tekanan kerja untuk hasil yang sempurna, pekerjaan merupakan karir bergengsi, mentaati kode etik kerja, mengembangkan keahlian lain. Faktor nilai sosial, terdiri dari 4 (empat) indikator, yaitu: kesempatan mengikuti kegiatan sosial, kebebasan berinteraksi, memberikan rasa senang, menyalurkan hobi. Faktor pasar kerja kerja, terdiri dari 5 (lima) indikator, yaitu: kesempatan kerja yang menjamin, kemudahan mengakses lowongan pekerjaan, riang dan percaya diri, menjalin kesepakatan, emosi yang baik.

Indikator yang mewakili setiap variabel yang mempengaruhi pemilihan karir non pendidikan lulusan Sarjana Pendidikan Ekonomi tahun 2017 Fakultas Ekonomi Universitas Pendidikan Ganesha adalah: Faktor penghargaan finansial diwakili oleh indikator gaji yang cukup dengan faktor loading 0.673. Faktor Pelatihan Profesional oleh indikator pelatihan luar lembaga dengan faktor loading 0.514. Faktor Lingkungan Kerja diwakili oleh indikator faktor mengembangkan keahlian lain loading 0.258. Faktor Nilai Sosial untuk hasil yang sempurna oleh indikator memberikan rasa senang dengan faktor loading 0.171. Faktor Pasar Kerja diwakili oleh indikator menjalin kesepakatan dengan faktor loading 0.274. Dengan demikian faktor dominan yang paling mempengaruhi pemilihan karir non kependidikan lulusan sarjana Pendidikan Ekonomi tahun 2017 Universitas Pendidikan Ganesha adalah Faktor Penghargaan Finansial.

Berdasarkan simpulan di atas, maka saran-saran yang dapat diajukan bagi alumni dalam dalam pemilihan karir adalah: Diharapkan dapat mengutamakan memilih jalur pendidikan yang dapat memberikan peluang karir yang menjanjikan dan sesuai dengan jurusannya. Diharapkan sebelum menentukan pilihan karir dapat menganalisis beberapa jenis karir yang cocok dengan kepribadian dan sesuai dengan pengetahuan yang dimiliki agar mampu melaksanakan tugas yang diberikan

\section{DAFTAR PUSTAKA}

Agus Widarjono. 2010. Analisis Statistika Multivariat Terapan. Yogyakarta: UPP STIM YKPN.

Akbar. 2011. Teori Perkembangan Karir. Yogyakarta: Pustaka Belajar.

Husaini, Usman dan Purnomo Setiadi Akbar. 2009. Metodologi Penelitian Sosial. Jakarta: Bumi Aksara.

Arikunto dan Suharsimi. 2006. Prosedur Penelitian Suatu Pendekatan Praktek. Jakarta: Rineka Cipta.

Azwar, Saifudin. 2004. Pengantar Psikologi Intelegensi. Yogyakarta: Pustaka Belajar. 
Borchert, M. 2002. Career Choice Factors of High School Students Teory. Tesis (tidak diterbitkan). Univercuty of Wisconsin, Stout.

Dariyo. Agoes. 2004. Psikologi Perkembangan Remaja. Bogor: Ghalia Indonesia.

Dariyo, Agoes. 2004. Psikologi Perkembangan Dewasa Muda. Jakarta: Grasindo

Desmita. 2008. Psikolog perkembangan. Bandung: Remaja rosdakarya.

Djamarah. Syaiful Bahri dan Aswan Zain. 2007. Strategi Belajar Mengajar. Jakarta: PT Rineka Cipta

Eny, Kusriyanti. 2008. Faktor-faktor yang mempengaruhi Minat Mahasiswa Akuntansi dalam Memilih Karir di Bidang Akuntansi. Skripsi (tidak diterbitkan). Universitas Gajah Mada.

Gibson, R. L. dan Mitchell, M. H. 1995. Intoduction to Counseling and Guidance, Englewood Cliffs. New Jersey: Prentice-Hall Inc.

Gladding. 2012. Bimbingan Konseling. Bandung: Angkasa.

Gujarati, Damodar N. 2007. Dasardasar ekonometrika. Jakarta: PT Gelora Aksara Pratama.

Harahap, Sofyan Syafri. 2013. Analisis Kritis Atas Laporan Keuangan, Cetakan Kesebelas. Jakarta: Rajawali Pers.

Hasan, Iqbal. 2009. Analisis data penelitian dengan statistik. Cetakan keempat. Jakarta: PT. Bumi aksara.
Luthans, Fred. 2006. Perilaku Organisasi, Edisi Kesepuluh. Yogyakarta: Penerbit Andi.

Luthans, Fred. 2006. Perilaku Organisasi, Edisi Kesepuluh. Yogyakarta: Penerbit Andi.

Nazir, Moh. 2011. Metode Penelitian. Cetakan 6. Bogor: Ghalia Indonesia.

Sharf, R. S. 2010. Apllying Career Development Theory to Counseling. Belmont: Brook/Cole Cengage Learning.

Slameto. 2010. Belajar dan Faktor faktor yang Mempengaruhi. Jakarta: PT. Rineka Cipta.

Sudarmanto R. G., 2005, Analisis Regresi Linier Ganda dengan SPSS, Edisi Pertama. Yogyakarta: Graha IImu.

Sugiyono. 2016. Metode Penelitian Pendidikan Pendekatan Kualitatif, Kuantitatif, dan $R \& D$. Bandung: Alfabeta.

Suyono. 2014. Teoori Pemilihan Karir. Bandung: Gramedia.

Tohardi, Ahmad. 2002. Pemahaman Praktis Management Sumber Daya Manusia, Cetakan I. Bandung: CV. Mandar Maju

Winkel dan Sri Hartuti. 2013. Bimbingan dan Konseling di Institut Pendidikan. Yogyakarta: Media Abadi.

Yusuf, Muri. 2005. Kiat Sukses Dalam Karier. Bogor: Ghalia Indonesia. 